\title{
Desenvolvimento neuropsicomotor de crianças expostas à infecção congênita pelo Zika vírus
}

\section{Neuropsychomotor development of children with congenital Zika virus infection}

\author{
Anna Karolyne Kaimmi Lima e Souza Lopes ${ }^{1}$ (]) \\ Olga Akiko Takano² \\ Juliana Ilídio da Silva 3 (1)
}

\section{Vagner Ferreira do Nascimento 4 (1) Amanda Cristina de Souza Andrade 5 (1) Ana Claudia Pereira Terças-Trettel ${ }^{6}$ (i)}

${ }^{1}$ Autora para correspondência. Universidade do Estado de Mato Grosso (Cuiabá). Mato Grosso, Brasil. anna.lopes@unemat.br 2,3,5Universidade Federal de Mato Grosso (Cuiabá). Mato Grosso, Brasil. oatakano@gmail.com, julianailidio_enf@hotmail.com, amandasouza_est@yahoo.com.br 4,6Universidade do Estado de Mato Grosso (Cuiabá). Universidade Federal de Mato Grosso (Cuiabá). Mato Grosso, Brasil. vagnerschon@hotmail.com, ana.claudia@unemat.br

RESUMO | INTRODUÇÃO: A comprovação da associação de microcefalia no Brasil com a infecção congênita pelo Zika vírus, leva a necessidade de estudos sobre a repercussão no desenvolvimento das crianças decorrentes do comprometimento do sistema nervoso central (SNC). OBJETIVO: Avaliar o desenvolvimento neuropsicomotor (DNPM) de crianças expostas à infecção congênita pelo Zika vírus e sua associação com características e diagnósticos pré natais, neonatais e pós natais da mãe/criança. MÉTODOS: Estudo transversal com crianças de zero a três anos, nascidas entre 2015 e 2018, classificadas com infecção congênita pelo Zika vírus. Na coleta das características clínicas e sócio demográficas, utilizou-se um questionário semiestruturado e na avaliação do DNPM o Teste de Triagem de Denver II. Na associação, utilizou-se o teste exato de Fisher $(p<0,05)$. RESULTADOS: Avaliou-se 30 crianças, 46,67\% apresentavam alterações do DNPM, os maiores foram na linguagem $(46,67 \%)$ e motricidade fina (43,33\%). 23,33\% tinham mais que 24 meses, idade que se associou a alterações do DNPM $(p<0,012)$. A infecção predominou entre 4 e 12 semanas de gestação e obteve associação com os atrasos do DNPM ( $p<0,002)$. 46,67\% das crianças apresentaram microcefalia e $40 \%$ calcificações cerebrais, ambos com associação a atrasos no DNPM $(p<0,001)$. Em exame físico 36,7\% apresentaram alterações de postura e persistência de reflexos primitivos, $40 \%$ hiperirritabilidade, 33,33\% disfagia e deformidades articulares, todas com associação importante com as alterações no DNPM $(p<0,001)$. CONCLUSÕES: Crianças expostas à infecção congênita pelo Zika vírus apresentaram atrasos no DNPM e quanto mais precoce a infecção na gravidez, maior o envolvimento do sistema nervoso central.

PALAVRAS-CHAVE: Gestação. Zika vírus. Transtornos do Neurodesenvolvimento.
ABSTRACT | INTRODUCTION: The proof of the association of microcephaly in Brazil with congenital Zika virus infection leads to the need for studies on the impact on children's development resulting from the involvement of the central nervous system (CNS). OBJECTIVE: To evaluate the neuropsychomotor development (NPMD) of children exposed to congenital Zika virus infection and its association with prenatal, neonatal, and postnatal characteristics and diagnoses of the mother/child. METHODS: Cross-sectional study with children aged zero to three years, born between 2015 and 2018, classified with congenital Zika virus infection. In the collection of clinical and socio-demographic characteristics, a semistructured questionnaire was used, and the Denver II Screening Test was used to assess the DNPM. In the association, Fisher's exact test was used $(p<0.05)$. RESULTS: Thirty children were evaluated; $46.67 \%$ had DNPM alterations, the greatest ones were in the language (46.67\%) and fine motor skills (43.33\%). $23.33 \%$ were older than 24 months, an age-associated with changes in DNPM $(p<0.012)$. Infection predominated between 4 and 12 weeks of gestation and was associated with DNPM delays ( $p<0.002$ ). 46.67\% of children had microcephaly and $40 \%$ cerebral calcifications, both associated with DNPM delays $(p<0.001)$. On physical examination, $36.7 \%$ had changes in posture and persistence of primitive reflexes, 40\% hyperirritability, 33.33\% dysphagia, and joint deformities, all with an important association with changes in DNPM $(p<0.001)$. CONCLUSIONS: Children exposed to congenital Zika infection had developmental delays. It is noteworthy that the earlier the infection in pregnancy, the greater the involvement of the central nervous system of children.

KEYWORDS: Gestation. Zika virus. Neurodevelopmental Disorders. 


\section{Introdução}

O desenvolvimento neuropsicomotor (DNPM) é um processo multidimensional e integral, tem como efeito tornar a criança capaz de responder às suas necessidades e às do meio ambiente; engloba o crescimento físico, aquisições relacionadas à cognição, linguagem, habilidades motora, função sensorial, desenvolvimento sócio emocional, comportamental e a maturação neurológica, essa que ocorre principalmente na primeira infância, entre 29 dias a 2 anos e é considerada a melhor fase para estímulo do desenvolvimento. .-4 $^{-4}$

O bom desempenho nessa etapa resulta-se da interação entre fatores intrínsecos e extrínsecos à criança. Entre os fatores intrínsecos estão os riscos assistenciais e os biológicos, sendo esse considerado eventos e infecções pré natais, neonatais e pós-natais. Os fatores extrínsecos compreendem aos riscos relacionados às condições ambientais, sociais e culturais, que se encontra à criança. Quando esses fatores atuam de forma negativa sobre a maturação neurológica, possibilitam o aumento de danos no DNPM, passam então a serem considerados como fatores de riscos para o desenvolvimento infantil. ${ }^{3-\underline{-}}$

Entre os fatores de risco intrínsecos, destacam-se as infecções congênitas que alteram o bom funcionamento do SNC, como a neurogênese, o crescimento dendrítico e axonial, a sinapse e a mielinização. Nesse contexto insere-se o Zika vírus, flavivírus da família Flaviviridae, descoberto no continente africano, em 20 de abril de 1947, é um patógeno infeccioso altamente teratogênico (capacidade de produzir malformações congênitas) e neurotrópico (predileção a neurônios). ${ }^{1,5,7,8}$

No ano de 2015, o Zika vírus foi associado à grave infecção congênita com consequências diretas para o SNC, os acometimentos característicos como microcefalia grave, córtex cerebrais finos, calcificações subcorticais, cicatriz macular e pigmentação focal da retina, deram origem a Síndrome da Zika Congênita. 9 Desde então, inicialmente foi considerado, pelo Ministério da Saúde (MS), e, sequencialmente, pela Organização Mundial da Saúde (OMS), como uma emergência de saúde pública internacional. ${ }^{10}$

Na recém conhecida Síndrome da Zika Congênita, foi associado, concomitante aos danos do SNC, diversos sinais clínicos que comprometem o DNPM, como hipertonia, contraturas de início precoce, persistência de reflexos primitivos, consequências para visão e audição, convulsões, hiperexcitabilidade, disfagia, crescimento intrauterino inferior ao esperado, baixo peso ao nascer, entre outros. Os resultados dos estudos ainda incluem desaceleração do crescimento do perímetro cefálico pós-natal.

Sabe-se até o momento que o atraso no DNPM das crianças irá depender do grau de lesão do SNC e em qual período da idade gestacional ocorreu à infecção pelo Zika vírus. Há relatos de que quanto mais precoce a infecção durante a gestação, maior o número de alterações cerebrais. ${ }^{8}$ A literatura também menciona que quanto mais antecipado ocorrer às medidas de diagnóstico e intervenção nessas crianças, menores serão os impactos ao desenvolvimento e na vida futura das mesmas. 10

A gravidade da infecção congênita pelo Zika vírus e suas repercussões na infância foram demonstradas ao mundo, pela primeira vez, no Brasil. Os acometimentos para o SNC e DNPM alcançaram grandes proporções, assim como a dificuldade no diagnóstico precoce e inserção das crianças acometidas nos tratamentos adequados, revelando a carência mundial de informações sobre o assunto. Esse cenário demonstra real necessidade de estudos sobre o DNPM dessas crianças e análises sobre a repercussão que a infecção congênita provocará ao seu desenvolvimento., $2,5,11$

Para abordar essa lacuna importante do conhecimento, este estudo propôs avaliar o DNPM, entre as idades de 0 a 3 anos, etapa mais importante do desenvolvimento infantil, de crianças nascidas de mães com diagnóstico confirmado ou provável de Zika vírus no período pré-natal e associá-lo com as características e diagnósticos pré natais, neonatais e pós natais da mãe/criança.

\section{Métodos}

Todos os aspectos éticos de pesquisa com seres humanos foram respeitados com respectiva aprovação do Comitê de Ética e Pesquisa em Seres Humanos. Igualmente, os responsáveis pelas crianças assinaram o Termo de Consentimento Livre e Esclarecido (TCLE). 
Trata-se de estudo de corte transversal com crianças entre zero a três anos, nascidas no período de 2015 a 2018, notificadas como casos confirmados e/ou prováveis de infecção congênita pelo Zika vírus. Os serviços para avaliação foram escolhidos por fazerem parte da rede de atendimento de gestantes com suspeita de infecção pelo Zika vírus.

Em conjunto, para detecção de casos confirmados e/ou prováveis da infecção sem diagnóstico laboratorial foram utilizadas as recomendações clínicas e epidemiológicas do Ministério da Saúde (MS). ${ }^{2}$ Excluíram-se os lactentes com microcefalia e/ou perímetro cefálico <-2 desvios-padrão para idade/sexo de etiologia genética e mães expostas a substâncias com potencial teratogênico durante a gestação. ${ }^{1}$

A amostra foi de conveniência, onde procurou-se colocar todas as crianças dos serviços de saúde que poderiam participar das avaliações. O levantamento foi realizado no período de maio a setembro de 2018, através de todos os prontuários dos serviços de saúde (setor de Comissões de Controle de Infecção Hospitalar) que fizeram parte da pesquisa e que indicavam contato com Zika vírus durante a gestação; totalizaram-se 150 crianças identificadas.

Em seguida, nos prontuários, coletou-se o telefone dos pais, entrou-se em contato para esclarecimento da pesquisa, convidando-os para a mesma; depois do aceite, realizou-se o agendamento para preenchimento do TCLE e avaliação das crianças. Dos convites realizados por telefone, 11 mães recusaram mesmo com proposta de avaliação em domićlio, 109 não foram encontradas por preenchimento incorreto dos contatos telefônicos e endereços nos prontuários. Portanto, ao final, a população foi constituída de 30 crianças, conforme detalhado no fluxograma (Figura 1).

Figura 1. Fluxograma de seleção dos casos

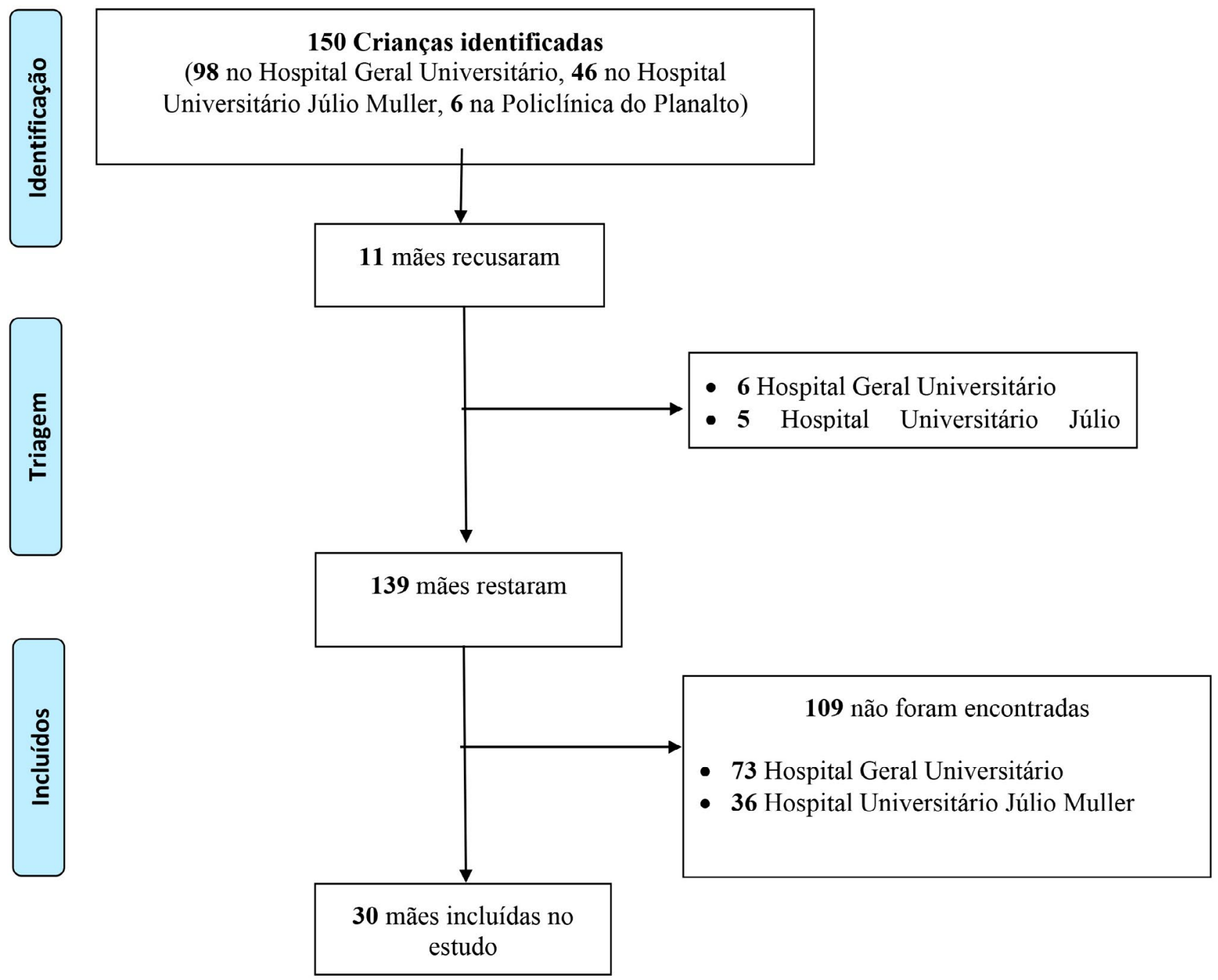


As avaliações foram conduzidas até outubro de 2018. As coletas de dados foram realizadas em local reservado, com duração de 50 a 60 minutos, direcionada por meio de roteiro semiestruturado, composto por informações pessoais, gestacionais, parto e história atual da criança, as informações coletadas de todas as fases (pré-natais, neonatais e pós-natais) foram feitas num único encontro com os pais, através da anamnese detalhada, dos exames que traziam e da caderneta de saúde das crianças. A avaliação do desenvolvimento neuropsicomotor deu-se pela aplicação do Teste de Triagem de Denver II (TTDDII), realizado pela fisioterapeuta e mestranda autora da pesquisa, segundo o manual original de instrução de Frankenburg e Doods ${ }^{15}$, adaptado no Brasil por Souza et al. ${ }^{16}$, que permite avaliar os quatro campos do desenvolvimento: pessoal social, motor fino-adaptativo, linguagem e motor grosso. A descrição detalhada sobre a aplicação do TTDDII pode ser verificada em publicações anteriores. ${ }^{15,16}$

Segundo o TTDDII, os resultados do DNPM foram considerados: normal, quando as crianças não apresentavam nenhum atraso ou apenas uma cautela em todas as provas realizadas nos quatro setores; suspeita, apenas um atraso ou duas ou mais cautelas, e anormal, aquelas com dois ou mais atrasos. Para fins de análise estatística, as classificações suspeitas e anormais foram reagrupadas como alterados, e os normais, categorizados como adequados. Dessa forma, a variável dependente foi o desempenho alterado ou adequado no TTDDII.

As variáveis independentes do estudo foram: características relacionadas à mãe e criança, condições socioeconômicas e diagnósticos pré-natais, neonatais e pós-natais. Quanto às características relacionadas à mãe e condições socioeconômicas, avaliou-se: idade por faixa etária, renda familiar, escolaridade da mãe, idade gestacional do diagnóstico da infecção por Zika vírus, febre e exantema na gestação.

As variáveis relacionadas às características da criança incluem: sexo, idade em meses, classificação do recém-nascido (termo, pré-termo, pré-termo tardio/ moderado), acompanhamento profissional para o DNPM. Peso de nascimento/atual, comprimento de nascimento/estatura atual, perímetro cefálico de nascimento/atual, todos seguindo a classificação da OMS que quando necessário, considera escore- $Z$ para idade e sexo: 'muito baixo', crianças com desvios-padrão <-3; 'baixo', desvio-padrão entre -3 e -2; 'adequado', com desvio-padrão $>-2 \cdot \frac{15,16}{16}$
As variáveis independentes relacionadas aos diagnósticos pré-natais, neonatais e pós-natais foram: microcefalia (escore-Z para idade e sexo); calcificações cerebrais em exame de imagem; Brainstem Evoked Response Audiometry (BERA) alterado (integridade das vias auditivas), alterações de postura, persistência de reflexos primitivos (RTCA e RTCS), hiperexcitabilidade/ hiperirritabilidade, disfagia, deformidades articulares de membros e hipertonia. Todas as variáveis foram obtidas por meio dos registros dos prontuários dos serviços, documentos (exames de imagens, laudos laboratoriais e caderneta de saúde da criança) e entrevista com os pais ou responsáveis.

Inicialmente, para auxiliar as análises, as variáveis contínuas foram agrupadas em categorias. Após, realizou-se a tabulação das variáveis, calculando-se as frequências que fizeram parte do corpo das tabelas; isso é, a frequência absoluta simples e frequência relativa simples.

Em seguida, realizou-se uma análise bivariada em que a escolha do teste se deu de acordo com tamanho da amostra. O teste exato de Fischer é preciso para todos os tamanhos amostrais, e foi usado para estudar a associação entre as variáveis categóricas independentes (relacionadas à mãe, condições socioeconômicas e diagnósticos pré-natais, neonatais e pós-natais) e a variável categórica dependente (Teste de Triagem de Denver II).

Foi utilizado o Software Microsoft Excel, versão 2010, para construção do banco de dados e para análise, o pacote estatístico STATA versão 12. Considerando nível de significância de 5\% ( $p$-valor < 0,05).

\section{Resultados}

Das 30 crianças expostas ao Zika vírus no período gestacional, 46,67\% apresentaram alterações de qualquer ordem no TTDD II. Em relação aos campos do desenvolvimento, 36,67\% apresentaram alteração no setor pessoal social, $43,33 \%$ no motor fino, $46,67 \%$ na linguagem e $40 \%$ no setor motor grosso.

Nos diagnósticos do SNC, 14 das 30 crianças avaliadas $(46,67 \%)$ apresentaram perímetro cefálico inferior para idade gestacional durante o pré-natal $\left(12^{\circ}\right.$ a $20^{\circ}$ semana), dessas mesmas crianças, 12 (40\%) nasceram com microcefalia e duas com perímetro cefálico 
adequado, porém, após o $1^{\circ}$ mês de vida, todas as 14 (46,67\%) tiveram perímetro cefálico abaixo do adequado e evoluíram de fato com microcefalia, sugerindo, assim, uma microcefalia tardia em duas crianças. As calcificações cerebrais foram presentes em 12 das 30 crianças (40\%) ainda durante o pré-natal, o que persistiu ao nascimento e após o $1^{\circ}$ mês de vida. Observa-se que os $40 \%$ de crianças que apresentaram calcificações cerebrais também apresentaram microcefalia, mas nem toda criança que apresentou microcefalia $(46,67 \%)$ demonstrou igualmente calcificações cerebrais (Tabela 1).

No exame clínico do BERA, 14 das 30 crianças (46,67\%) apresentaram alterações ainda ao nascer; dessas crianças, 12 (41,38\%) de fato apresentaram alterações do BERA após o $1^{\circ}$ mês de vida. No exame físico 11 crianças (36,7\%) apresentaram alterações de postura e persistência de reflexos primitivos ao nascer e após o $1^{\circ}$ mês de vida; 12 (40\%) apresentaram hiperexcitabilidade/hiperirritabilidade ao nascer e após o $1^{\circ}$ mês de vida; 10 (33,33\%) apresentaram disfagia e deformidade articulares ao nascer e após o $1^{\circ}$ mês de vida; 11 (36,67\%) apresentaram hipertonia ao nascer e após $1^{\circ}$ mês de vida (Tabela 1 ).

Tabela 1. Distribuição de frequências das variáveis relacionadas aos diagnósticos pré-natais, neonatais e pós-natais das crianças expostas ao Zika vírus no período gestacional

\begin{tabular}{|c|c|c|c|c|c|c|}
\hline \multirow[t]{2}{*}{ Variáveis } & \multicolumn{2}{|c|}{ Durante o pré-natal } & \multicolumn{2}{|c|}{$\begin{array}{l}\text { Ao nascer e no } 1^{\circ} \text { mês } \\
\text { de vida }\end{array}$} & \multicolumn{2}{|c|}{ Após $1^{\circ}$ mês de vida } \\
\hline & $\mathbf{n}$ & $\%$ & $\mathbf{n}$ & $\%$ & $\mathbf{N}$ & $\%$ \\
\hline Microcefalia & 14 & 46,67 & 12 & 40,00 & 14 & 46,67 \\
\hline Calcificações cerebrais & 12 & 40,00 & 12 & 40,00 & 12 & 40,00 \\
\hline BERA $^{b}$ alterado & $N A^{a}$ & $N A^{a}$ & 14 & 46,67 & 12 & 41,38 \\
\hline Alterações de postura & $N A^{a}$ & $N A^{a}$ & 11 & 36,67 & 11 & 36,67 \\
\hline $\begin{array}{l}\text { Persistência de reflexos } \\
\text { primitivos }\end{array}$ & $N A^{a}$ & $N A^{a}$ & 11 & 36,67 & 11 & 36,67 \\
\hline Hiperexcitabilidade & $N A^{a}$ & $N A^{a}$ & 12 & 40,00 & 12 & 40,00 \\
\hline Hiperirritabilidade & $N A^{a}$ & $N A^{a}$ & 12 & 40,00 & 12 & 40,00 \\
\hline Disfagia & $N A^{a}$ & $N A^{a}$ & 10 & 33,33 & 10 & 33,33 \\
\hline Deformidade articulares & $N A^{a}$ & $N A^{a}$ & 10 & 33,33 & 10 & 33,33 \\
\hline Hipertonia & $N A^{a}$ & $N A^{a}$ & 11 & 36,67 & 11 & 36,67 \\
\hline
\end{tabular}

$\mathrm{Na}$ associação de microcefalia com alterações no desenvolvimento, após o $1^{\circ}$ mês de vida, 12 das 14 das crianças com microcefalia (85,71\%) tiveram desempenho alterado no TTDII com associação estatística significativa entre ambos $(p<0,001)$. As $12(100 \%)$ crianças identificadas com calcificações cerebrais tiveram alterações no desenvolvimento e associação estatística significativa com o TTDDII $(p<0,001)$ (Tabela 2).

Nas alterações do exame clínico do BERA, após o $1^{\circ}$ mês de vida, 11 das 12 crianças identificadas (91,67\%) apesentaram dificuldades no desenvolvimento com associação estatística significativa com o TTDDII $(p<0,001)$. Todas as crianças (100\%) que apresentaram alteração nos exames físicos (alterações posturais, persistência de reflexos primitivos, hiperexcitabilidade/hiperirritabilidade, disfagia, deformidades articulares e hipertonia) demonstraram dificuldades no desenvolvimento, ao nascer e permanecendo após o $1^{\circ}$ mês de vida, com associação estatística significativa com o TTDDII $(p<0,001)$ (Tabela 2$)$. 
Tabela 2. Associação entre Teste de Triagem de Denver II e os diagnósticos pré-natais, neonatais e pós-natais das crianças expostas ao Zika vírus no período gestacional

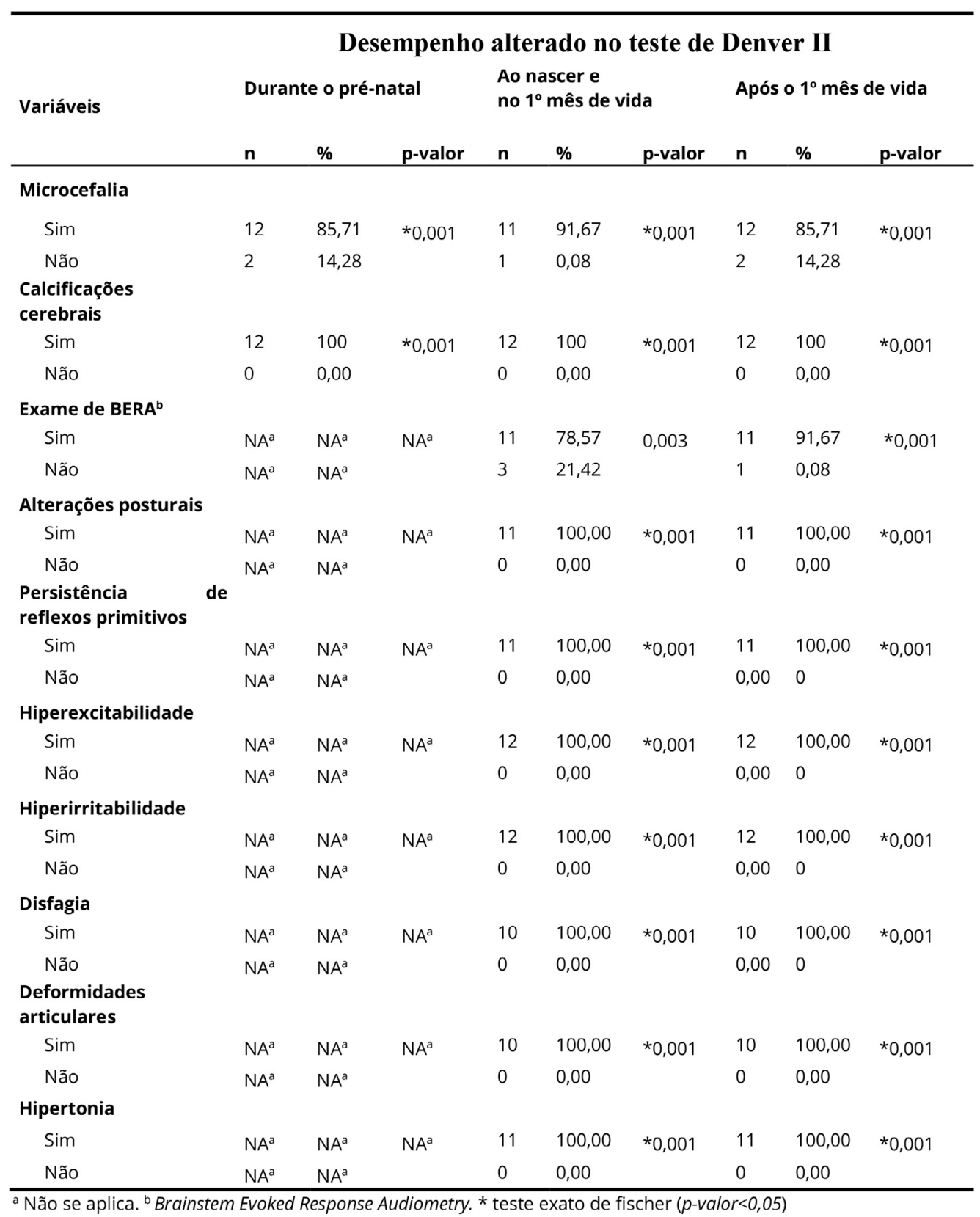


Nas características sociodemográficas 56,67\% tinha entre 20 e 29 anos, 26,67\% estavam entre 30 a 35 anos e $16,67 \% 35$ anos ou mais, sendo que nesse último grupo concentrou-se o maior número de crianças (60\%) com alteração no TTDII, no entanto não houve associação significativa. Na renda familiar mensal 53,33\% das mães relataram menos que $R \$ 1.300$ e $46,67 \%$ entre $R \$ 1.300$ a $R \$ 6.000$, observa-se que $62,50 \%$ das crianças com alteração estiveram no grupo de renda menor de $\mathrm{R} \$ 1.300$. (Tabela 3).

Em relação a escolaridade da mãe 60\% estiveram entre 0 e 8 anos e $40 \% 9$ anos ou mais, em números absolutos os dois grupos tiveram igualmente crianças com alterações no DNPM. Entre as idades das crianças $40 \%$ tinham menos de 12 meses, 36,67\% entre 12 e 24 meses e 23,33\% tinham 24 meses ou mais, sendo que o maior percentual de crianças $(85,71 \%)$ com alteração no desenvolvimento tinha 24 ou mais meses de idade, o que demonstrou associação estatística significativa $(p<0,012)$ com desempenho alterado no TTDII (Tabela 3).

Tabela 3. Associação entre o Teste de Denver Il e características sóciodemográficas da mãe e das crianças expostas ao Zika no período gestacional, Cuiabá - MT, 2018

\begin{tabular}{|c|c|c|c|c|c|}
\hline \multirow[t]{2}{*}{ Variáveis } & \multicolumn{2}{|c|}{ Geral } & \multicolumn{2}{|c|}{$\begin{array}{l}\text { Desempenho alterado } \\
\text { no teste de Denver II }\end{array}$} & \multirow[t]{2}{*}{ p-valor } \\
\hline & $\mathbf{n}$ & $\%$ & $\mathbf{n}$ & $\%$ & \\
\hline \multicolumn{6}{|c|}{ Faixa etária da mãe } \\
\hline 20 a 29 & 17 & 56,67 & 9 & 52,94 & \multirow[b]{3}{*}{0,421} \\
\hline 30 a 35 & 8 & 26,67 & 2 & 25,00 & \\
\hline 35 ou mais & 5 & 16,67 & 3 & 60,00 & \\
\hline \multicolumn{6}{|c|}{ Renda familiar (reais) } \\
\hline Menos de 1300 & 16 & 53,33 & 10 & 62,50 & \multirow[t]{2}{*}{0,067} \\
\hline 1300 a 6000 & 14 & 46,67 & 4 & 28,57 & \\
\hline \multicolumn{6}{|c|}{ Escolaridade da mãe (anos) } \\
\hline 0 a 8 & 18 & 60,00 & 7 & 38,89 & \multirow[t]{2}{*}{0,457} \\
\hline 9 ou mais & 12 & 40,00 & 7 & 58,33 & \\
\hline \multicolumn{6}{|c|}{ Idade da criança (meses) } \\
\hline Menor que 12 & 12 & 40,00 & 2 & 16,67 & \\
\hline Entre 12 e 24 & 11 & 36,67 & 6 & 54,55 & \multirow[b]{2}{*}{$*_{0,012}$} \\
\hline 24 ou mais & 7 & 23,33 & 6 & 85,71 & \\
\hline \multicolumn{6}{|l|}{ Sexo da criança } \\
\hline Masculino & 19 & 63,33 & 10 & 52,63 & \multirow[t]{2}{*}{0,466} \\
\hline Feminino & 11 & 36,67 & 4 & 36,36 & \\
\hline
\end{tabular}

O diagnóstico da infecção pelo Zika vírus predominou entre 4 a 12 semanas de gestação $(63,33 \%)$, sendo que a maior parcela $(68,42 \%)$ das crianças com alteração no desenvolvimento era desse grupo, obtendo associação estatística significativa entre contaminação precoce na gestação e desempenho alterado no TTDII $(p<0,002)$. Observa-se que 12 (40\%) crianças com perímetro cefálico muito baixo ao nascimento e $14(46,67 \%)$ com perímetro cefálico baixo e muito baixo atual são as que mais apresentaram alterações do desenvolvimento com associação significativa com TTDII ( $p<0,001)$, o que corrobora os achados de microcefalia apresentados. Curiosamente, as crianças que mais tiveram atrasos no desenvolvimento $(92,31 \%)$ foram aquelas que realizavam acompanhamento profissional para estímulo do DNPM com associação estatística significativa com TTDDII $(p<0,001)($ Tabela 4$)$. 
Tabela 4. Associação entre o Teste de Triagem Denver Il e características relacionadas à mãe e das crianças expostas ao Zika vírus no período gestacional

\begin{tabular}{|c|c|c|c|c|c|}
\hline \multirow[t]{2}{*}{ Variáveis } & & \multicolumn{2}{|c|}{$\begin{array}{l}\text { Desempenho alterado } \\
\text { no teste de Denver II }\end{array}$} & \multirow[t]{2}{*}{ p-valor } \\
\hline & $\mathbf{n}$ & $\%$ & $\mathbf{n}$ & $\%$ & \\
\hline \multicolumn{6}{|c|}{$\begin{array}{l}\text { Idade gestacional do diagnóstico da } \\
\text { infecção por Zika vírus (semanas) }\end{array}$} \\
\hline 4 a 12 & 19 & 63,33 & 13 & 68,42 & $*_{0,002}$ \\
\hline 13 a 38 & 11 & 36,67 & 1 & 9,09 & \\
\hline \multicolumn{6}{|l|}{ Febre durante a gestação } \\
\hline Sim & 25 & 83,33 & 10 & 40,00 & 0,157 \\
\hline Não & 5 & 16,67 & 4 & 80,00 & \\
\hline \multicolumn{6}{|c|}{$\begin{array}{l}\text { Histórico de exantema na gestação durante } \\
\text { a gestação }\end{array}$} \\
\hline Sim & 27 & 90,00 & 11 & 40,74 & 0,090 \\
\hline Não & 3 & 10,00 & 3 & 100,00 & \\
\hline \multicolumn{6}{|c|}{ Classificação do recém-nascido } \\
\hline Termo & 25 & 83,33 & 12 & 48,00 & 1,000 \\
\hline Pré-termo & 4 & 13,33 & 2 & 50,00 & \\
\hline Pré-termo moderado & 1 & 3,33 & 0 & 0,00 & \\
\hline \multicolumn{6}{|c|}{ Peso de nascimento (gramas) } \\
\hline 1500 a 2499 & 5 & 16,67 & 2 & 40,00 & 1,000 \\
\hline 2500 ou mais & 25 & 83,33 & 12 & 48,00 & \\
\hline \multicolumn{6}{|c|}{ Peso atual (escore Z para idade/sexo) } \\
\hline Adequado & 21 & 70,00 & 8 & 38,10 & \\
\hline Baixo & 7 & 23,33 & 4 & 57,14 & 0,237 \\
\hline Muito baixo & 2 & 6,67 & 2 & 100,00 & \\
\hline \multicolumn{6}{|c|}{$\begin{array}{l}\text { Comprimento de nascimento (escore Z para } \\
\text { idade/sexo) }\end{array}$} \\
\hline Adequado & 20 & 66,67 & 9 & 45,00 & 0,840 \\
\hline Baixo & 1 & 3,33 & 1 & 100,00 & \\
\hline Muito baixo & 9 & 30,00 & 4 & 44,44 & \\
\hline \multicolumn{6}{|l|}{ Estatura atual (escore Z) } \\
\hline Adequado & 22 & 73,33 & 10 & 45,45 & \\
\hline Baixa & 7 & 23,33 & 3 & 42,86 & 0,830 \\
\hline Muito baixa & 1 & 3,33 & 1 & 100,00 & \\
\hline \multicolumn{6}{|c|}{$\begin{array}{l}\text { Perímetro cefálico de nascimento } \\
\text { (escore Z) }\end{array}$} \\
\hline Adequado & 18 & 60,00 & 3 & 16,67 & \\
\hline Muito baixo & 12 & 40,00 & 11 & 91,67 & $*_{0,001}$ \\
\hline \multicolumn{6}{|c|}{ Perímetro cefálico atual (escore Z) } \\
\hline Adequado & 16 & 53,33 & 2 & 12,5 & \\
\hline Baixo & 9 & 30,00 & 9 & 100,00 & $*_{0,001}$ \\
\hline Muito baixo & 5 & 16,67 & 5 & 100,00 & \\
\hline \multicolumn{6}{|c|}{$\begin{array}{l}\text { Realiza acompanhamento profissional para } \\
\text { o DNPM }\end{array}$} \\
\hline Sim & 13 & 43,33 & 12 & 92,31 & $*_{0,001}$ \\
\hline Não & 17 & 56,67 & 2 & 11,76 & \\
\hline
\end{tabular}

* teste exato de fischer $(p$-valor $<0,05)$ 


\section{Discussão}

O desenvolvimento neuropsicomotor possui estreita e complexa relação com diversos fatores intrínseco e extrínsecos. Modelos hierarquizados para o estudo de seus determinantes e inter-relações facilitam esse entendimento. $\underline{\underline{?}}$

Do ponto de vista epidemiológico, o modelo analítico dos determinantes sociais de saúde de Mosley e Chen (2003) e os fatores de risco apontados pelo MS estipulam três níveis de fatores que se inter-relacionam e alteram o desfecho dos casos: proximais (agem diretamente sobre o desfecho), intermediários e distais. A partir desse modelo, pode-se considerar a exposição pelo Zika vírus durante a gestação., ${ }^{3,6}$

Entre os determinantes proximais e intermediários, com ação direta ao SNC, estão os fatores maternos como a infecção congênita pelo Zika vírus, idade gestacional da exposição, sinais clínicos como febre e exantema; fatores das crianças como estímulo profissional ao DNPM, idade da criança relacionada ao início dos sintomas, características clínicas/físicas e os diagnósticos pré-natais, neonatais e pós-natais das mesmas. Entre os determinantes distais, estão o nível socioeconômico e baixa renda familiar.,3,4

O presente estudo mostrou que o maior percentual de mães era jovem, com escolaridade e renda familiar baixa, que relataram a infecção ainda no início da gestação, sendo que nas duas últimas características, seus filhos apresentaram os maiores atrasos no desenvolvimento segundo o TTDDII. ${ }^{17-19}$

Quanto a esses determinantes distais, Freitas et al. ${ }^{17}$ corroboram com os achados desse estudo, pois descrevem que o perfil sociodemográfico das mães que tiveram infecção congênita pelo Zika vírus é composto em sua maioria por mulheres jovens, com baixa escolaridade e baixa renda. A escolaridade materna e renda familiar mensal produzem efeitos sobre a carga e qualidade dos estímulos ofertados, assistência à saúde e educação, estando essas condições relacionadas ao DNPM das crianças. No presente estudo não houve associação significativa entre o TTDD II e essas variáveis; o que pode ter contribuído para esse resultado é a homogeneidade da amostra quanto às características sociais descritas.., 12
Com relação aos determinantes proximais, características da mãe, os resultados encontrados mostraram que quase todas relataram sinais clínicos prováveis da infecção, como febre e exantema, resultados semelhantes foram observados em outros estudos sobre a infecção congênita pelo Zika vírus. $\frac{18}{}$ Concomitantes aos relatos de exantema e febre, a maioria das mães apresentou a infecção ainda no início da gestação, sendo essa preditora de diferentes prevalências na gravidade de sequelas da criança. ${ }^{19}$

Diversos autores já demonstraram que quanto mais antecipada for à infecção congênita na idade gestacional, principalmente no $1^{\circ}$ e início do $2^{\circ}$ trimestres, fase essencial para formação dos neurônios e sinapses, mais graves serão os acometimentos para o SNC, podendo evoluir para Síndrome da Zika Congênita, com maiores probabilidades de anomalias cerebrais e sequelas que comprometem o DNPM dessas crianças. 1ํ-22 Esses achados reforçam as nossas análises, em que foram encontradas associações entre exposição à infecção congênita no início da gestação e atrasos no DNPM.

Crianças com 24 ou mais meses de idade apresentaram maiores atrasos no desenvolvimento com associação significativa com o TTDDII. Uma primeira reflexão é que conforme a criança cresce seus repertórios neuropsicomotores vão se refinando, fazendo com que tenham mais necessidade em explorar o mundo e consequentemente, demandem mais recursos, acesso a materiais adequados, maior estimulação pessoal, todos esses aspectos dependem de bons níveis sociais e econômicos, que conforme descritos, concentram-se numa minoria da amostra. ${ }^{15,16}$

A segunda hipótese deve-se ao fato das crianças com idades entre dois e três anos avaliadas terem nascido no período inicial do surto no Brasil (2015/2016), mesmo período de pouco conhecimento sobre a doença/agravo e do potencial de morbidade em crianças, dificultando as medidas de diagnósticos e encaminhamento precoce aos tratamentos adequados, repercutindo no atraso do DNPM. 2,7,23 Cabe destacar que mais da metade das crianças avaliadas recebiam acompanhamento profissional para o desenvolvimento, mas, ainda assim, foram as que mais apresentaram alterações no DNPM, denotando que possivelmente demoraram a ter acesso aos serviços de estimulação precoce. $\underline{\underline{5}}$ 
Nos Estados Unidos, uma coorte de crianças nascidas de mães com infecção confirmada ou provável pelo Zika vírus na gestação demonstrou que a identificação e intervenção precoce de eventos adversos no desenvolvimento neurológico foram determinantes para melhorar o funcionamento cognitivo, social e comportamental. Recomenda-se que o momento mais crítico para intervir é durante os primeiros três anos, propondo avaliação multiprofissional padronizada ao nascimento e a cada consulta. $\underline{\underline{23}}$

No Brasil, recomenda-se assistência precoce as crianças acometidas pela infecção congênita do Zika vírus e que seja realizada por uma equipe multidisciplinar, destacando-se pediatras, neurologistas, fisioterapeutas, terapeutas ocupacionais e fonoaudiólogos. ${ }^{4,13}$ Essas informações corroboram com o estudo atual, em que possivelmente a falta de estimulação precoce foi fator decisivo nos prognósticos de maiores alterações.

Nos determinantes proximais com ação direta ao SNC, ao se tratar do sinal clínico da microcefalia a literatura relata que crianças expostas a infecção por Zika vírus no período gestacional, podem desenvolvê-la. A microcefalia é caracterizada por um perímetro cefálico inferior ao esperado para idade e sexo. Segundo a Organização Mundial de Saúde é uma malformação de etiologia complexa e multifatorial, envolvendo fatores genéticos e ambientais, identificada através da medição do perímetro cefálico. Pode ser classificada conforme o tempo do seu início em congênita, ou seja, já está presente ao nascimento ou microcefalia pós-natal, quando ocorre falha de crescimento normal do perímetro cefálico após o nascimento..$^{1,2}$

A ocorrência dessa malformação não significa necessariamente que ocorram alterações motoras ou cognitivas, pois a medida do perímetro cefálico pode não refletir um cérebro anormalmente pequeno com redução dos neurônios; pode ocorrer de crianças com microcefalia terem o DNPM normal, quando essa é de origem familiar ou sem etiologia, assim como ao oferta-se o estímulo adequado durante a primeira infância, favorecendo a maturação neurológica e a neuroplasticidade. ${ }^{1.13}$ Esses relatos corroboram com nossos achados em que duas crianças com microcefalia não apresentaram complicações motoras e grandes acometimentos cerebrais.
Porém, outros estudos explicam que $90 \%$ dos casos dos casos de microcefalia são acompanhados de alterações ${ }^{1,13}$ e que crianças com microcefalia, devido à infecção por Zika vírus, podem apresentar importantes comprometimentos neurológicos que dificultam o progresso do DNPM, associando-se com alterações motoras e cognitivas que variam de acordo com o grau e extensão do acometimento cerebral, além de déficits auditivos, visuais, físicos e intelectuais. $\frac{722}{}$

Flor et al. avaliaram o desenvolvimento de lactentes com infecção congênita pelo Zika vírus e microcefalia e constataram comprometimentos graves, como dificuldades em rolar, engatinhar e dissociar cintura pélvica escapular, restringindo os principais padrões normais de movimentos para o desenvolvimento adequado 1,11 , confirmando nossos achados, em que houve associação significativa de microcefalia e atrasos no DNPM em $85,71 \%$ das crianças.

Entre as anormalidades cerebrais, assim como nesse estudo, outros achados no Brasil identificaram que crianças com confirmação da infecção tiveram alterações em exames de imagem, como as calcificações cerebrais, além de retardo do perímetro cefálico pósnatal com microcefalia no $5^{\circ}$ mês de vida. ${ }^{8}$

O desenvolvimento pós-natal da microcefalia em crianças com infecção congênita do Zika vírus foi relatada anteriormente; van der Linden et al. .8 descreveram 13 bebês com a infecção em tempos variáveis da gestação. Foram encontrados diversos achados como disfagia, epilepsia, irritabilidade, graus de hipertonia e hemiparesia. A microcefalia não foi evidenciada ao nascimento, mas todas as crianças evoluíram com microcefalia pós-natal.

Esses relatos corroboram com os dados desse estudo, em que duas crianças evoluíram com microcefalia após o primeiro mês de vida, fornecendo evidências de que entre bebês com exposição pré-natal ao Zika vírus, a ausência de microcefalia ao nascimento não exclui a infecção congênita e nem a regressão do crescimento cerebral tardiamente, pois o crescimento cerebral continua após o nascimento, até os três primeiros anos de vida do indivíduo, além de apoiar as recomendações de que tais crianças necessitam de acompanhamento médico precoce mesmo sem sintomas motores ou microcefalia ao nascimento, $, 14,21$ 
No que se refere à avaliação do DNPM de crianças com infecção congênita pelo Zika vírus e alteração nos exames de neuroimagem, Moreira et al..24 apontaram que crianças com imagem cerebral normal tiveram $20 \%$ menos chances de atraso no desenvolvimento quando comparadas aquelas com imagem cerebral anormal. As informações descritas reforçam as desse estudo, pois foram observadas associações significativas entre atrasos no desenvolvimento e alterações neurorradiológicas.

Entre os transtornos no aparelho locomotor, verificou-se alta prevalência nas crianças acometidas pela infecção congênita pelo Zika vírus, e quando associadas às alterações no desenvolvimento, se tornaram unânimes. Das alterações do DNPM de qualquer ordem, as mais prevalentes foram os atrasos na linguagem e no aspecto motor. Outros estudos já evidenciaram que os atrasos no desenvolvimento dessa população afetam principalmente a linguagem e a motricidade., $, 1,21$

Essas crianças podem nascer com postura inadequada resultante de deformidades articulares e de membros, como pés tortos congênitos, luxação de quadril, artrogripose e podem manter reflexos que normalmente deveriam desaparecer conforme o crescimento (RTCA e RTCS). Todos esses são sintomas de comprometimentos neurológicos com sinais de envolvimento extrapiramidal, o que dificultam a aprendizagem de novas habilidades com consequências ao DNPM. .9

Outro estudo mostrou que estas crianças têm em comum a hiperreflexia e hipertonia, desenvolvimento atípico e déficit na função manual, relatando que após o nascimento, ainda no primeiro trimestre de vida, já é possível identificar sinais de lesões cerebrais graves a partir dessas anormalidades presentes no tônus muscular e na persistência dos reflexos primitivos, corroborando com nossas análises, em que foi encontrada associação entre hipertonia/persistência de reflexos primitivos e alterações no desenvolvimento desde o $1^{\circ}$ mês de vida. $\underline{20}$

Evidencia-se ainda, na literatura, sinal clínico referente a aspectos fonoarticulatórios, sendo mais prevalente a incoordenação na função de sucção com consequente evolução para disfagia, igualmente demonstrado num maior número de crianças avaliadas, com associação importante aos distúrbios no desenvolvimento. Essa característica justifica-se em virtude de lesão em diversas estruturas que fazem conexões com o centro da deglutição, como o cerebelo, núcleos da base, tálamo e região córticosubcortical, regiões também associadas aos aspectos da coordenação, equilíbrio, motricidade fina e aprendizagem. $\frac{14,20}{20}$

Esse estudo apresentou como limitação o mau preenchimento dos registros e prontuários dos pacientes, a grande maioria com números de telefone, celular e endereços estavam incorretos ou incompletos, impossibilitando o contato, o que também comprometeu o número da amostra. Devido à identificação de diversos preenchimentos inadequados, suspeita-se que as classificações das mães em relação ao contágio por Zika vírus na gestação não estejam totalmente corretos, por isso para tentar diminuir provável erro de identificação, foi realizado a anamnese detalhada com a mãe, utilizando também as recomendações clínicas e epidemiológicas do MS ${ }^{11}$ e buscando quando necessários exames de comprovação da infecção. Além disso, deve-se considerar que as crianças integrantes do estudo não foram avaliadas quanto a transtornos do espectro autista.

\section{Considerações finais}

Crianças com infecção congênita pelo Zika vírus apresentam atrasos importante no DNPM, principalmente linguagem e motricidade fina, associados às alterações no SNC, sendo que quanto mais alterações no SNC, maiores serão os comprometimentos ao desenvolvimento. Adicionalmente, identificou-se que quanto mais precoce a infecção ocorrer na gestação, maiores serão os acometimentos para o SNC concomitantes ao DNPM, e essas manifestações se tornam mais complexas ao se levar em consideração a relação temporal da faixa etária e circulação do agente etiológico e acesso precoce ao acompanhamento profissional para o DNPM.

Observa-se ainda que a ausência de microcefalia no nascimento não descarta a infecção na gestação e outros comprometimentos que possam ocorrer, bem como a possibilidade da ocorrência de microcefalia tardiamente nessas crianças. 
Ressalta-se a importância de políticas públicas que propiciem as crianças o acesso mais precoce aos tratamentos adequados no SUS, com avaliações periódicas, intervenção de equipe multiprofissional, visando otimizar ao máximo suas aquisições e minimizando os impactos das sequelas, facilitando a melhor evolução do desenvolvimento e qualidade de vida, além de acompanhamento psicológico e orientações aos pais.

\section{Contribuições dos autores}

Lopes AKKLS, Takano OA e Terças-Trettel ACP participaram da concepção, delineamento, busca e análise estatística dos dados da pesquisa, interpretação dos resultados e redação do artigo científico. Andrade ACS participou na análise dos dados e interpretação dos resultados. Nascimento VF e Silva JI participaram na redação do artigo científico.

\section{Conflitos de interesses}

Nenhum conflito financeiro, legal ou político envolvendo terceiros (governo, empresas e fundações privadas, etc.) foi declarado para nenhum aspecto do trabalho submetido (incluindo, mas não se limitando a subvenções e financiamentos, participação em conselho consultivo, desenho de estudo, preparação de manuscrito, análise estatística, etc.).

\section{Referências}

1. Nunes ML, Carlini CR, Marinowic D, Kalil Neto F, Fiori HH, Scotta MC, et al. Microcefalia e vírus Zika: um olhar clínico e epidemiológico do surto em vigência no Brasil. J Pediatr (Rio J). 2016;92(3):230-40. https://doi.org/10.1016/j.jped.2016.02.009

2. Ministério da Saúde (Brasil), Secretaria de Vigilância em Saúde. Orientações integradas de vigilância e atenção à saúde no âmbito da Emergência de Saúde Pública de Importância Nacional: procedimentos para o monitoramento das alterações no crescimento e desenvolvimento a partir da gestação até a primeira infância, relacionadas à infecção pelo vírus Zika e outras etiologias infeciosas dentro da capacidade operacional do SUS [Internet]. Brasília: Ministério da Saúde; 2017. Disponível em: https://bvsms.saude.gov.br/bvs/publicacoes/orientacoes integradas_vigilancia_atencao_emergencia_saude_publica.pdf

3. Ministério da Saúde (Brasil). Atenção humanizada ao recémnascido de baixo peso: método canguru: manual técnico [Internet]. Brasília: Ministério da Saúde; 2013. Disponível em: https://bvsms.saude.gov.br/bvs/publicacoes/atencao humanizada_recem_nascido_canguru.pdf
4. Ministério da Saúde (Brasil), Secretaria de Atenção à Saúde. Diretrizes de estimulação precoce: crianças de zero a 3 anos com atraso no desenvolvimento neuropsicomotor decorrente de microcefalia [Internet]. Brasília: Ministério da Saúde; 2016. Disponível em: https://bvsms.saude.gov.br/bvs/publicacoes/ diretrizes_estimulacao_criancas_0a3anos_neuropsicomotor.pdf

5. Ministério da Saúde (Brasil), Secretaria de Vigilância em Saúde. Vírus Zika no Brasil: a resposta do SUS [Internet]. Brasília: Ministério da Saúde; 2017. Disponível em: https://bvsms.saude. gov.br/bvs/publicacoes/virus_zika_brasil_resposta_sus.pdf

6. Ribeiro DG, Perosa GB. Padovani FHP. Fatores de risco para o desenvolvimento de crianças atendidas em Unidades de Saúde da Família, ao final do primeiro ano de vida: aspectos sociodemográficos e de saúde mental materna. Ciênc Saúde Colet. 2014;19(1):215-26. https://doi.org/10.1590/1413$\underline{81232014191.1904}$

7. Avelino MOA, Ferraz PCS. Análise do desenvolvimento neuropsicomotor em crianças com síndrome pós-zika vírus: um estudo transversal. Rev Pesqui Fisioter. 2018;8(2):147-54. http:// dx.doi.org/10.17267/2238-2704rpf.v8i2.1799

8. van der Linden V, Pessoa A, Dobyns W, Barkovich AJ, van der Linden Jr H, Rolim Filho EL, et al. Description of 13 infants born during october 2015-january 2016 with congenital zika virus infection without microcephaly at birth - Brazil. MMWR Morb Mortal Wkly Rep 2016;65(47):1343-8. https://doi.org/10.15585/ mmwr.mm6547e2

9. Moore CA, Staples JE, Dobyns WB, Pessoa A, Ventura CV, Fonseca $\mathrm{EB}$, et al. Characterizing the pattern of anomalies in congenital Zika syndrome for pediatric clinicians. JAMA Pediatr. 2017;171(3):288-95. https://doi.org/10.1001/ jamapediatrics.2016.3982

10. Besnard M, Dub T, Gérardin P. Outcomes for 2 children after peripartum acquisition of Zika virus infection, French Polynesia, 2013-2014. Emerg Infect Dis. 2017;23(8):1421-3. https://doi. org/10.3201/eid2308.170198

11. Flor CJDRV, Guerreiro CF, Anjos JLM. Desenvolvimento neuropsicomotor em crianças com microcefalia associado ao zika vírus. Rev Pesqui Fisioter. 2017;7(3):313-18. http://dx.doi. org/10.17267/2238-2704rpf.v7i3.1386

12. Lowe R, Barcellos C, Brasil P, Cruz OG, Honório NA, Kuper H, et al. The zika virus epidemic in Brazil: from discovery to future implications. Int J Environ Res Public Health. 2018;15(1):96-114. https://doi.org/10.3390/ijerph15010096

13. Eickmann SH, Carvalho MDCG, Ramos RCF, Rocha MAW, van der Linden V, Silva PFS. Síndrome da infecção congênita pelo vírus Zika. Cad Saúde Pública. 2016;32(7):e00047716. https://doi. org/10.1590/0102-311X00047716 
14. Pessoa A, van der Linden V, Yeargin-Allsopp M, Carvalho MDCG, Ribeiro EM, Braun KVN, et al. Motor abnormalities and epilepsy in infants and children with evidence of congenital Zika virus infection. Pediatrics. 2018;141(Suppl 2):S167-79. https://doi. org/10.1542/peds.2017-2038F

15. Frankenburg WK. Preventing developmental delays: is developmental screening sufficient? Pediatrics. 1994;93(4):586-93. Citado em: PMID: 7510874

16. Souza SC, Leone C, Takano AO, Moratelli HB. Desenvolvimento de pré-escolares na educação infantil em Cuiabá, Mato Grosso, Brasil. Cad Saúde Pública. 2008;24(8):1917-26. https://doi. org/10.1590/S0102-311X2008000800020

17. Freitas PSS, Soares GB, Mocelin HJS, Lacerda LCX, Prado $T N$, Sales CMM, et al. Síndrome congênita do vírus Zika: perfil sociodemográfico das mães. Rev Panam Salud Publica. 2019;43:e24. https://dx.doi.org/10.26633\%2FRPSP.2019.24

18. Duarte G, Moron AF, Timerman A, Fernandes CE, Mariani Neto C, Almeida Filho GL, et al. Infecção do vírus Zika em gestantes e microcefalia. Rev Bras Ginecol Obstet. 2017;39(5):235-48. https:// doi.org/10.1055/s-0037-1603450

19. Martins RS, Fróes MH, Saad LdC, Ignácio Junior SM, Prado WDA, Figueiredo EM, et al. Descrição dos casos de síndrome congênita associada à infecção pelo ZIKV no estado de São Paulo, no período 2015 a 2017. Epidemiol Serv Saúde. 2018;27:e2017382. https://doi.org/10.5123/S167949742018000300012
20. Botelho ACG, Neri LV, Silva MQF, Lima TT, Santos KG, Cunha RMA, et al. Infecção congênita presumível por Zika vírus: achados do desenvolvimento neuropsicomotor - relato de casos. Rev Bras Saude Mater Infant. 2016;16 (Suppl 1):S45-50. https://doi. org/10.1590/1806-9304201600S100004

21. Feitosa IML, Schuler-Faccini L, Sanseverino MTV. Aspectos importantes da Síndrome da Zika Congênita para o pediatra e o neonatologista. Bol Cient Pediatr [Internet]. 2016;05(3):7580. Disponível em: https://www.sprs.com.br/sprs2013/ bancoimg/170118173954bcped_05_03_a02.pdf

22. Ribeiro BNF, Muniz BC, Gasparetto EL, Ventura N, Marchiori E. Síndrome congênita pelo vírus Zika e achados de neuroimagem: o que sabemos até o momento?. Radiol Bras. 2017;50(5):314-22. https://doi.org/10.1590/0100-3984.2017.0098

23. Rice ME, Galang RR, Roth NM, Ellington SR, Moore CA, Valencia-Prado M, et al. Vital Signs: Zika-Associated Birth Defects and Neurodevelopmental Abnormalities possibly associated with congenital zika virus infection - U.S. Territories and Freely Associated States. MMWR Morb Mortal Wkly Rep. 2018;67(31):858-67. https://doi.org/10.15585/mmwr.mm6731e1

24. Moreira MEL, Nielsen-Saines K, Brasil P, Kerin T, Damasceno L, Pone M. Neurodevelopment in infants exposed to Zika virus in utero. New England Journal of Medicine. 2019;379(24):2377-79. https://doi.org/10.1056/nejmc1800098 